\title{
Efficacy of STC in Magnetically Coupled High Frequency Power Electronics Systems: Full-Bridge DC-DC Converter
}

This paper was downloaded from TechRxiv (https://www.techrxiv.org).

\section{LICENSE}

CC BY 4.0

SUBMISSION DATE / POSTED DATE

08-09-2021 / 18-10-2021

\section{CITATION}

Paul, Arun (2021): Efficacy of STC in Magnetically Coupled High Frequency Power Electronics Systems: FullBridge DC-DC Converter. TechRxiv. Preprint. https://doi.org/10.36227/techrxiv.16584125.v2

$\mathrm{DOI}$

10.36227/techrxiv.16584125.v2 


\title{
Efficacy of STC in Magnetically Coupled High Frequency Power Electronics Systems: Full-Bridge DC-DC Converter
}

\author{
Arun Kumar Paul, Senior Member, IEEE
}

\begin{abstract}
Due to its simple gain selection and implementation procedures high-gain sliding mode control idea was introduced. Apart from achieving robustness features, the aim was to reduce product-design cycle time. To overcome its basic chattering issues, it was replaced by complex super twisting control (STC). Subsequently, the research in this field has been extensive, intense and persistent. The idea has been validated in several applications generating great hope in minds of industry experts. Its real success, however, would depend on its adoption and diffusion into industry domain, where an analysis of validating STC based products is due. In STC, selection of gains is based on worst-case values of disturbance and/or its derivative. Can such procedure ensure controller's reliable functioning? This article proposes that such simplistic procedure of gain selection may not work for power electronics controllers where, particularly, the actuation or controlled power transfer to load is through magnetically-coupled system. Using practical approach, this article elaborates that optimally designed transformer, driven by high-gain super twisting controller, invites problem of core saturation leading to higher switching losses, poor operating duty cycle of the system and there could be problem of reliability. It further details an alternate high-gain controller that generates superior efficacy.
\end{abstract}

Index Terms - Constant current (CC) load, full-bridge DC-DC converter (FBC), proportional plus integral (PI) control, second order sliding mode control (SOSMC), super twisting control (STC), transformer core saturation.

\section{INTRODUCTION}

G RADUALLY, for effective and efficient use, major part Tof energy demand would be handled through compatible power electronics systems [1]-[4]. Full-bridge converter FBC (see Fig. 1) is one popular configuration being used for control of power flow to wide range high-power applications [4]-[8]. It consists of several functional blocks, such as,

1. Power converter and topologies [8] used, therein

2. Transformer for isolation and voltage translation [9]

3. Sensors and actuators [10]

4. Embedded system [11]

5. Control concepts [11]-[22], etc.

Ideally, for effective utility of each block, they should be functionally compatible to each other; should not pose as any constraint to other. Then, say, for control of secondary side outputs (e.g., current $I_{\mathrm{a}}$ or voltage $V_{\mathrm{L}}$ ), the system in Fig. 1 could be represented as secondary side controller (see Fig. 2a).

The author is with Messieurs Electronics Devices World Wide Pvt. Ltd, 22 Mistry Industrial Estate, MIDC, Andheri, Mumbai 400093, India. (email: arunp26@iitbombay.org).
In industrial domains, the utility of PI control [11]-[15] is unmatched. Since its inception its application potential was recognized and the concept was soon integrated into industrial control system applications. Due to integral action, it could achieve zero steady state error in presence of uncertainty [13]. PI control is conservative because its two gains are chosen based on the desired response characteristics involving the complete dynamical system that includes the power controller. The gain selection is flexible to desired response characteristics.

The super twisting control (STC) [16]-[22] is an improved version of chattering-prone discontinuous sliding mode control function [23], the control is continuous. Though, it is perceived, at least, in theoretical domain, as a superior concept, its utility in industrial applications is still to be demonstrated [24], [25]. From industry perspective, it is important to analyze the issue in details purely in practical domain.

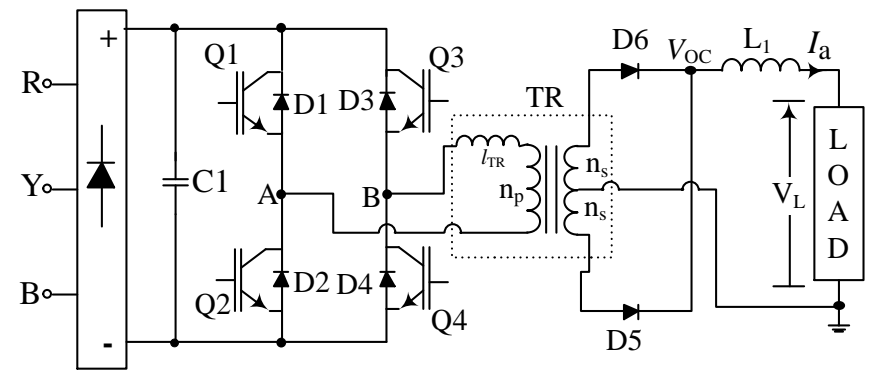

Fig. 1: Typical power circuit full-bridge DC-DC converter

Like PI control, STC also needs setting of two control loop gains [21], [22]. But, the approach of gain selection is different, it is based on the magnitude of matched disturbances present in process or load. Neither the primary side of transformer TR (see Fig. 1) nor the inverter switching frequency $f_{\mathrm{s}}$ plays any role in gain selection. Compared to PI, value of each gain is large. It makes the duty cycle $d_{\mathrm{pwm}}$ of PWM pulses sensitive to error. For magnetically coupled controlled actuation, fast rate of change in $d_{\mathrm{pwm}}$, caused by disturbance or ripple content in STC function, could make adverse impact on nonlinear magnetic circuit. The prospect of DC bias in core would be more [26][28]. Presence of DC flux in nonlinear core would result increase in power loss in inverter of multiple origin. The worst could lead to core saturation where one pair of devices draw large magnetizing current and incur large power loss at turn off. There could be pre-matured thermal tripping of the controller 
and or even failure of power devices. The article analyzes with detailed practical demonstration that high gain fractional order STC function may be less effective in control application where power transformer is part of controlled energy transfer to the load. The article is structured as follows: Section II briefly discusses a typical FBC. It further elaborates the results of PI concept for control of current for a particular load profile. Section III develops one STC based SOSM controller for the same load profile, and further validates the concept with superior control response. Section IV elaborates the final step of an innovation process i.e., complete the product validation. It details that STC fails to clear a magnetically coupled product on several fronts such as power loss, availability and reliability issues, etc. Finally, Section V, details, with practical validation, an alternate high-gain control function to achieve robust control of secondary side variables with superior effectiveness.

\section{FB DC-DC CONVERTER AND PI CONTROL}

FBC of Fig. 1 could be used for control of current or voltage $V_{\mathrm{L}}$ of load. Though, load characteristics compatible several soft switched topologies exist, for clarity, hard-switched version would be used for analysis. It is compatible to any transient load conditions. It consists of power inverter, transformer TR, secondary side fast rectifier and an inductor L1. Due to large RMS current capability, metallized polypropylene (MKP) capacitor is used in DC link for $\mathrm{C}_{\mathrm{DC}}$. Turn-on loss of inverter is small because each IGBT turns-on at half of $V_{\mathrm{DC}}$. For ideal TR with zero leakage inductance $l_{\mathrm{TR}}$, IGBTs turn-off at peak magnetizing current $I_{\mathrm{m}}$, not dependent on load current. Then, turn-off loss of each IGBT and recovery and conduction losses of diodes D1-D4 would as well be small. The value of switching frequency $f_{\mathrm{s}}$ could be increased if SiC Mosfets are used in place of Q1-Q4, or, SiC diodes are used in place of D1-D4. Here, as representative load, constant current (CC) arc welding process would be considered. Ideally, from control perspectives of secondary variables, FBC could be represented as shown in Fig. 2a. When either pair of (Q1, Q4 or Q2, Q3) or equivalently Q5 turns on the dynamics of current $I_{\mathrm{a}}$ is expressed as,

$\frac{d}{d t}\left(I_{a}\right)=\frac{1}{L_{1}}\left(V_{o c}-V_{L}\right)=\frac{1}{L_{1}}\left(\frac{V_{d c}}{n} d_{p w m}-V_{L}\right)$

Where $n$ is turns ratio of TR. When Q1-Q4 or Q5 is turned off, D5/D6 or equivalently D8 conducts, the dynamics of $I_{\mathrm{a}}$ is,

$\frac{d}{d t}\left(I_{a}\right)=\frac{1}{L_{1}}\left(-V_{L}\right)$

$V_{\mathrm{oc}}$ is controlled input voltage to arc circuit, $V_{\mathrm{L}}$ is arc voltage. $\mathrm{L} 1$, of significant value, is pre-requisite to contain ripple for wide range arc loads and also for ensuring arc stability. Furthermore, arc is extinguished when short-circuiting takes place, but the energy stored in it assists re-ignition of arc. During switching on and off of Q5 the desired current $I_{\mathrm{a}}$ in both cases are shown in Fig. 2b. For a particular application, with fixed ripple current $\Delta I_{a}$, the value of L1 depends on $f_{\mathrm{s}}$, because,

$L_{1}=\frac{1}{2 f_{s}} \frac{V_{L}\left(V_{o c}-V_{L}\right)}{\Delta I_{a} V_{o c}}$

At high $f_{\mathrm{s}}$, small value of L1 would ensure continuity of $I_{\mathrm{a}}$ for arc stability. To reduce associated high-frequency power loss, load-compatible soft-switching topologies [29], [30] are mostly adopted.

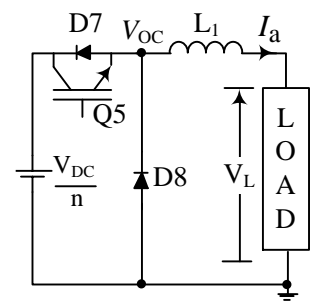

a)

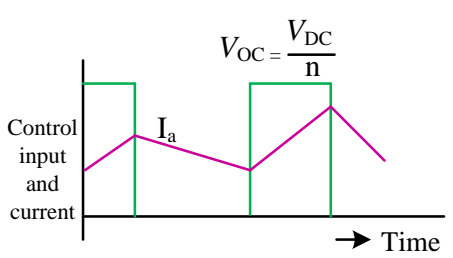

b)
Fig. 2: a) For secondary side control, ideal representation of full-bridge converter, and, b) Typical secondary side DC waveforms

\section{A. PI Control for Constant Current Applications}

For control of $I_{\mathrm{a}}$, the control inputs $V_{o c}$ in power domain and $u_{1}$ in control circuit are expressed as,

$V_{o c}=k_{1} u_{1}=\frac{d_{\mathrm{pwm}} V_{D C}}{n}=V_{o c}(\max ) d_{\mathrm{pwm}}$

$V_{\text {oc }}(\max )$ is maximum value of $V_{o c}$ and $k_{1}$ is constant. $V_{D C}$ is input voltage and $d_{\text {pwm }}$ is PWM duty cycle of inverter. PI control is mostly used in power electronics controllers. The PI control function for power actuation is,

$V_{o c}=K_{P} e+K_{I} \int e d t ; \quad e=I_{r e f}-I_{a}$

$K_{P}$ and $K_{I}$ are constant and $e$ is current error. In control domain, the PI function $u_{\mathrm{PI}}$ is modified as,

$u_{\mathrm{PI}}=\frac{K_{P}}{k_{1}} e+\frac{K_{I}}{k_{1}} \int e d t=k_{p} e+k_{i} \int e d t$

The closed loop transfer function $G_{\mathrm{CL}}(\mathrm{s})$ could be written as,

$G_{C L}(s)=\frac{\frac{1}{L_{1}}\left(K_{P} s+K_{I}\right)}{s^{2}+\frac{1}{L_{1}}\left(R_{L}+K_{P}\right) s+\frac{K_{I}}{L_{1}}}$

$R_{L}=V_{L} / I_{a}$ represents the equivalent resistive load in $V_{\mathrm{L}}$. The denominator $d(s)$ could be written as $d(s)=s^{2}+2 \xi \omega_{n}+\omega_{n}^{2}$ where L1 and $K_{\mathrm{I}}$ decide the natural frequency $\omega_{\mathrm{n}}$ and damping ratio $\xi$ depends on controller gain $K_{\mathrm{P}}$. In PI control, $\omega_{\mathrm{n}}$ is related to frequency ' $2 f_{s}$ ' of rectified voltage $V_{\text {oc }}$, like [14],

$\omega_{n}=\frac{2 f_{s}}{5 \xi}, \quad \tau_{c}=\frac{1}{\xi \omega_{n}}$ and, $\tau_{s}=4 \tau_{c}$

Where $\tau_{\mathrm{c}}$ is time constant of the system and $\tau_{\mathrm{S}}$ is settling time. To improve response time $\tau_{\mathrm{S}}, f_{\mathrm{s}}$ is increased.

Considering the value of $\xi$ as 0.8 , the value of $\omega_{\mathrm{n}}$ for $V_{\mathrm{oc}}$ at $40 \mathrm{kHz}$ is $10 \mathrm{kHz}$. The value of $K_{\mathrm{P}}$ and $K_{\mathrm{I}}$ are [12],

$K_{\mathrm{P}}=\left(2 \xi \omega_{n}-\frac{R_{L}}{L_{1}}\right) L_{1}$ and, $K_{\mathrm{I}}=L_{1} \omega_{n}^{2}$

Considering equivalent $\operatorname{arc} \operatorname{load} R_{\mathrm{L}}$ at $0.09 \Omega$ and L1 at $75 \mu \mathrm{H}$, the value $K_{\mathrm{P}}$ is 1.2 and $K_{\mathrm{I}}$ is 7500 .

\section{B. Practical Implementation of PI Control}

For practical validation, one $20 \mathrm{kHz}, 400 \mathrm{~A}$ FBC was developed. For sensing of $I_{a}$, a Hall effect-based transducer (output: $1 \mathrm{~A}=10 \mathrm{mV}$ ) was used. The value of $k_{1}$ was 8 . For practical implementation, for $u_{\mathrm{PI}}$, the value of $k_{\mathrm{p}}$ and $k_{\mathrm{i}}$ were 
chosen as 0.2 and 1000 respectively. At nominal $V_{\mathrm{DC}} 580 \mathrm{~V}$ the value of $V_{\text {oc }}(\max )$ was close to $80 \mathrm{~V}$.

Waveforms of different dynamic parameters for making two welding joints under different welding conditions are shown in Fig. 3. In arc welding occasional shorting of electrode with weld pool is considered as disturbance. Here, arc or load voltage $V_{\mathrm{L}}$ disappears, but current continues to flow through the electrode. Arc needs to be regained when shorting gets removed. It is clear from Fig. 3a, that while welding at $100 \mathrm{~A}$, in spite of overshoot and undershoot during the disturbances, there was no problem in making a good joint. Similarly, as shown in Fig. 3b, there was no problem of arc stability when welding was performed at higher current level 200A.

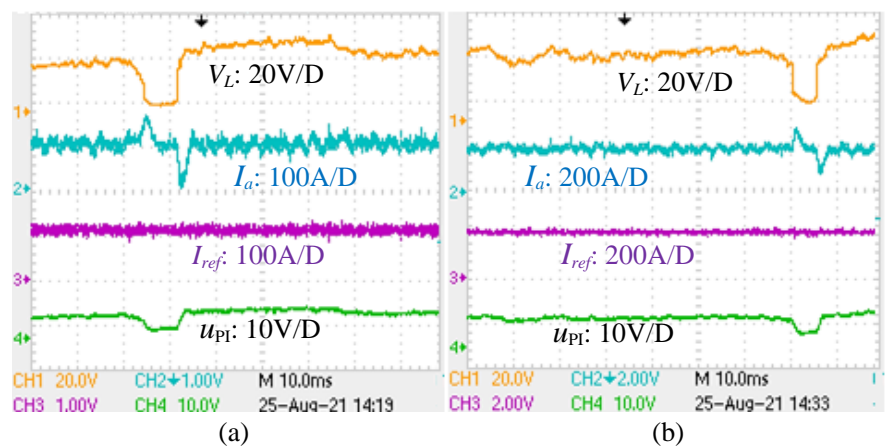

Fig. 3: There was no problem in welding, but, overshoot and undershoot were noticed in PI control $\left(k_{\mathrm{p}}=0.2\right.$ and $\left.k_{\mathrm{i}}=1000\right)$ : a) at small current of $100 \mathrm{~A}$, and, b) when current was increased to $200 \mathrm{~A}$. $\left[\mathrm{C}_{\mathrm{DC}}=55 \mu \mathrm{F}\right.$; L1 $\left.=50 \mu \mathrm{H}\right]$

\section{STC BASED DESIGN AND CONCEPT VALIDATION}

Gains in STC are decided based on the process disturbance, it needs the process or load to be clearly modelled. The arc is nonlinear. In stable welding arc zone, arc voltage $V_{\mathrm{L}}$ written is,

$V_{L}=V_{0}+E h_{a}+R_{a} I_{a}$

$E(\mathrm{~V} / \mathrm{m})$ is field intensity of arc, $V_{0}$ is anode and cathode drop together, $h_{\mathrm{a}}$ is arc length and $R_{\mathrm{a}}$ is arc resistance.

Considering error $e(6)$ as sliding surface, the objectives of SOSMC are to meet following conditions,

$e=I_{\text {ref }}-I_{a}=0$ and $\dot{e}=0$

The derivative of sliding surface $e$ for control of CC arc is,

$$
\begin{aligned}
\dot{e} & =-\dot{I}_{a}=\frac{1}{L_{1}} V_{o c}+\frac{1}{L_{1}} V_{L} \\
& =-\frac{1}{L_{1}} k_{1} u_{1}+\frac{1}{L_{1}}\left(V_{0}+E h_{a}+R_{a} I_{a}\right) \\
& =-\frac{1}{L_{1}} k_{1} u_{1}+\frac{1}{L_{1}} \psi
\end{aligned}
$$

The sliding surface can be steered into sliding manifold using STC, with following control function in power domain,

$V_{\mathrm{oc}}=k_{1} u_{\mathrm{STC}}=\rho_{0}|e|^{0.5} \operatorname{sgn}(e)+\rho_{1} \int \operatorname{sgn}(e) d \tau$

Where $\rho_{0}$ and $\rho_{l}$ are gains. The input $u_{\mathrm{STC}}$ in control circuit is

$u_{\mathrm{STC}}=\rho_{01}|e|^{0.5} \operatorname{sgn}(e)+\rho_{11} \int \operatorname{sgn}(e) d \tau$

The closed loop system with STC (13) is,
$\dot{e}=-\frac{\rho_{0}}{L_{1}}|e|^{0.5} \operatorname{sgn}(e)-\frac{\rho_{1}}{L_{1}} \int \operatorname{sgn}(e) d \tau+\frac{1}{L_{1}} \psi$

Let, $Z=-\frac{\rho_{1}}{L_{1}} \int \operatorname{sgn}(e) d \tau+\frac{1}{L_{1}} \psi$ then,

$\dot{Z}=-\frac{\rho_{1}}{L_{1}} \operatorname{sgn}(e)+\frac{1}{L_{1}} \dot{\psi}$

Where, $\psi=V_{L}$ and $\dot{\psi}=R_{a} \dot{I}_{a}$

Consider, the perturbation terms $\psi$ and $\dot{\psi}$ are bounded by,

$\delta_{1} \sqrt{|e|} \geq \psi$ and $\delta_{2} \geq \dot{\psi}$

Where $\delta_{1}$ and $\delta_{2}$ are constant $(>0)$. Compared to PI control, the approach for gain selection in STC is completely different. It is ignorant about the parameters of the inverter e.g., frequency $f_{\mathrm{s}}$, etc. For calculation of gains $\rho_{0}$ and $\rho_{1}$ the information on maximum or bounded value of matched disturbances $\psi$ and $\dot{\psi}$ are needed [22], they depend on process behavior. For CC process, at rated current of, say, 400A, the value of $\psi$ is $36 \mathrm{~V}$. Consider, conservatively the current error at $1.0 \%$ (i.e., $4 \mathrm{~A}$ ) of rated current and the value of $R_{\mathrm{a}}$ at $0.025 \Omega$. For different value of $\dot{I}_{1}$, the respective values of $\delta_{1}$ and $\delta_{2}$ are listed in Table I. For a dynamical system where $\dot{\psi}$ is dominant, compared to [22], the approach given [21] would yield smaller gains. To cater different transient conditions of the load, respective set of gains are listed in Table I. It is clear that for design of controller of complete multi-characteristic arc welding process [7], [17] the value of each gain would be large. Here, to study the efficacy of STC, simple CC arc load is considered where, even, $\dot{\psi}$ is ignored, here values of gains would be minimum (see Table I).

TABLE I

STC GAINS FOR DIFFERENT LEVELS OF DISTURBANCE LEVEL

\begin{tabular}{|c|c|c|c|c|c|c|}
\hline \multirow{2}{*}{} & \multicolumn{6}{|c|}{ STC gains at different value of $d I_{a} / d t$ or $d I_{\text {ref }} / d t \mathrm{~A} / \mathrm{s}$} \\
\cline { 2 - 7 } & 0 & 50000 & 50000 & 100000 & 300000 & $\geq 500000$ \\
\hline$\delta_{1}$ & 18 & 18 & 18 & 18 & 18 & 18 \\
\hline$\delta 2$ & 0 & 1250 & 1250 & 2500 & 7500 & $\geq 12500$ \\
\hline$\rho_{0}$ & 40 & 40 & 46 & 46 & 46 & 46 \\
\hline$\rho_{01}$ & 5 & 5 & 5.7 & 5.7 & 5.7 & 5.7 \\
\hline$\rho_{1}$ & $25 \mathrm{k}$ & $104 \mathrm{k}$ & $45.4 \mathrm{k}$ & $92 \mathrm{k}$ & $415 \mathrm{k}$ & $\geq 950 \mathrm{k}$ \\
\hline$\rho_{11}$ & 3125 & $13 \mathrm{k}$ & 5690 & $11.5 \mathrm{k}$ & $51.8 \mathrm{k}$ & $\geq 120 \mathrm{k}$ \\
\hline
\end{tabular}

\section{A. SOSMC Implementation}

Here, to validate the STC function, simplest dynamical situation of arc load was considered, the gains were selected based on minimum disturbance. The controller was analyzed for CC arc welding process where the disturbance $\dot{\psi}$ was zero. As shown in Table I, for $V_{\text {oc }}(13)$, the calculated gains were $\rho_{0}$ $(=40)$ and $\rho_{1}(>25000)$. To generate $u_{\text {STC }}(14)$, gains were changed to $\rho_{01}(=5.0)$ and $\rho_{11}(=3125)$. To validate high gain STC practically, hardware-based implementation was preferred for prompt corrective action where input (14) was simplified as,

$$
\begin{aligned}
u_{\mathrm{STC}}= & \rho_{01} k_{e} e+\rho_{11} \int \operatorname{sgn}(e) d \tau \\
& =\rho_{01}(e) e+\rho_{11} \int \operatorname{sgn}(e) d t
\end{aligned}
$$

Where, $k_{e}=1 / \sqrt{e}$ 
The error specific gains are listed in Table II. The hardware circuit for $u_{\mathrm{STC}}$ [19] was based on analog switch (see Fig. 5).

TABLE II

ERROR SENSITIVE EFFECTIVE GAIN VALUE

\begin{tabular}{ccccc}
\hline \hline $\begin{array}{c}\text { Sliding surface } \\
e, \mathrm{~V}\end{array}$ & $k_{e}$ & Switch active & $\rho_{01}(\mathrm{e})$ & $\rho_{01}(\mathrm{e})$ \\
\hline$\geq 2.0(\geq 200 \mathrm{~A})$ & 0.7 & All disabled & $0.7 \rho_{01}$ & 3.5 \\
$1.0(100 \mathrm{~A})$ & 1.0 & $\mathrm{~S} 1$ & $1.0 \rho_{01}$ & 5.0 \\
$0.5(50 \mathrm{~A})$ & 1.4 & $\mathrm{~S} 2$ & $1.4 \rho_{01}$ & 7.0 \\
$0.20(20 \mathrm{~A})$ & 2.24 & $\mathrm{~S} 3$ & $2.24 \rho_{01}$ & 11.2 \\
$0.04(4 \mathrm{~A})$ & 5.0 & $\mathrm{~S} 4$ & $5.0 \rho_{01}$ & 25.0 \\
\hline
\end{tabular}

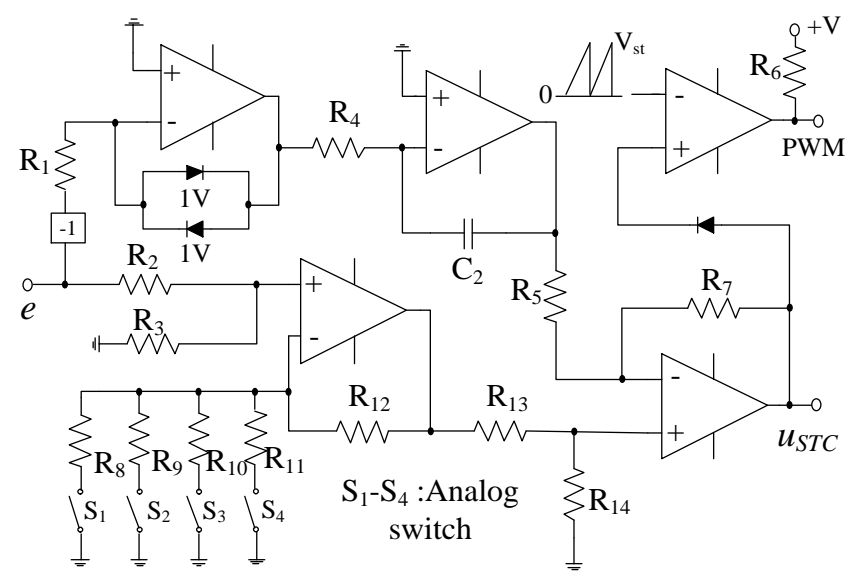

Fig. 4: Hardware circuit for implementation of the super twisting control

\section{B. Experimental Results of STC Controller}

STC controller needs to meet the desired performance in presence of wide range disturbances with multiple origin, like,

1. Sharp change in load or process disturbance

2. Sharp change in reference or process requirement

3. Increase in ripple content in error, particularly, at large current, caused by drooping nature of L1, and or,

4. Ripple content at source $V_{\mathrm{DC}}$ - due to availability of metallized polypropylene capacitors with large RMS current capability the value $C_{\mathrm{DC}}$ used is small.

Multiple experiments were conducted in actual applications. For concept validation, values of $C_{\mathrm{DC}}$ and $\mathrm{L} 1$ were varied. Initially, their values $\left(C_{\mathrm{DC}}=55 \mu \mathrm{F}\right.$ and $\left.\mathrm{L} 1=50 \mu \mathrm{H}\right)$ were kept same like PI control of Fig. 3. Fig. 5 shows waveforms of electrical variables for different welding conditions. Control of current while welding manually at $100 \mathrm{~A}$ (see Fig. 5a) during sudden load change was robust, there was no overshoot or undershoot. Similar control performance was noticed when at load current 200A (see Fig. 5b). When compared with PI control (see Fig. 3), performance of STC appeared to be superior, but interestingly, the ripple content in $u_{\mathrm{STC}}$ was more. Control response was robust (see Fig. 6a \& b) and ripple content in $u_{\mathrm{STC}}$ was reduced when L1 was increased to $75 \mu \mathrm{H}$. It was also noticed that the ripple content in $u_{\mathrm{STC}}$ further reduced when the value of $C_{\mathrm{DC}}$ was increased to $110 \mu \mathrm{F}$. Increase in value of $\mathrm{C}_{\mathrm{DC}}$ and $\mathrm{L} 1$ would increase cost and reduce power density, might not be acceptable in price sensitive competitive world.

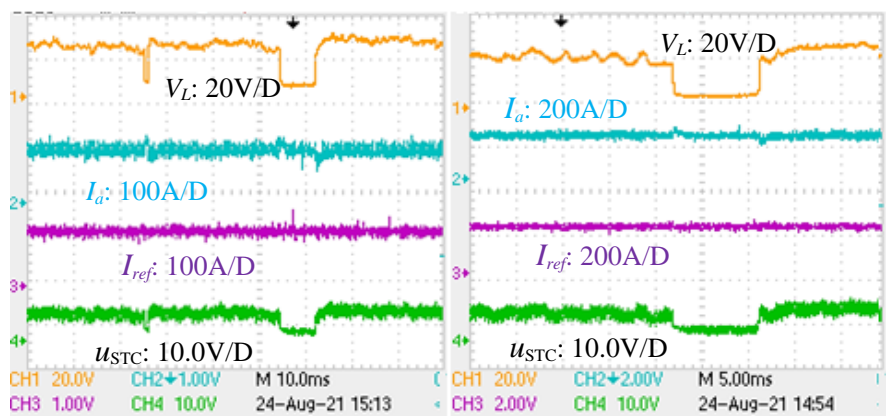

(a)

(b)

Fig. 5: STC could achieve robust control of current, but ripple in $u_{\text {STC }}$ was large at, a) current $100 \mathrm{~A}$, and, b) current $200 \mathrm{~A}$. $\left[\mathrm{L} 1=50 \mu \mathrm{H}\right.$ and $\left.\mathrm{C}_{\mathrm{DC}}=55 \mu \mathrm{F}\right]$

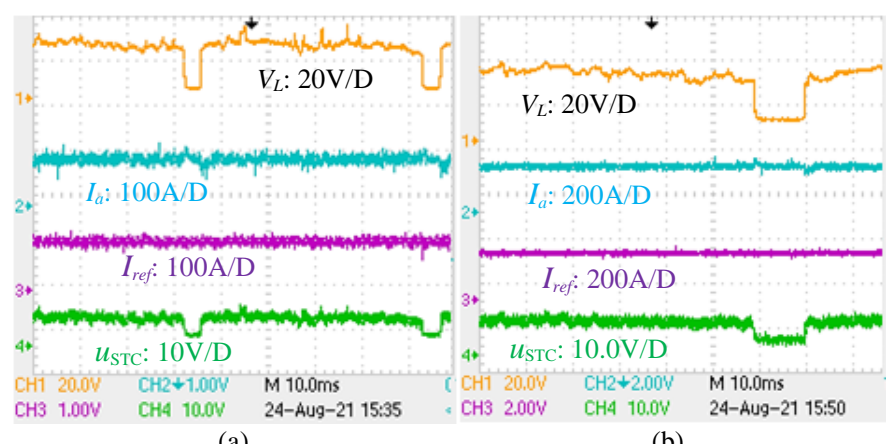

(a)

(b)

Fig. 6: Current control was robust and ripple in $u_{\mathrm{STC}}$ was reduced when L1 was increased to $75 \mu \mathrm{H}$ for welding at, a) $100 \mathrm{~A}$, and, b) $200 \mathrm{~A}$. [ $\left.C_{\mathrm{DC}}=55 \mu \mathrm{F}\right]$

\section{Product Validation of STC Based FBC}

Often, even practical validation of a concept might not be a good indicator for its adoption and diffusion into (certain) industry or commercial domains; at least, for SOSMC, it did not happen that way. Apart from demonstrating superior control performance against process disturbances, efficacy of STC could be judged if the concept mandatorily meets following criteria of the product deemed to be commercialized:

1. High degree of availability of the controller

2. Long service life i.e., the reliability estimate

3. Efficiency or power loss characteristics, and,

4. Cost competitiveness or

5. Favorable performance vs cost parameterization

While testing the controller for continuous duty applications in simple CC process, when compared with PI controller's performance, following observations were recorded:

1. STC controller's operating duty cycle (continuous run time in each ten-minute cycle) was much less. Due to frequent thermal shut down, its availability was poor.

2. The power losses in Q1-Q4 and D1-D4 were more

3. PWM controller entered cycle-by-cycle current mode shut-down frequently, and,

4. Prospect of IGBT failure increased, it would make impact on product reliability

Frequent erratic thermal shut-downs (at different value of $I_{\mathrm{a}}$ ) occurred from heatsink where Q1-Q4 were assembled. It meant that there was increase in power loss in inverter switches. Power loss in inverter switches could be categorized as follows: 
1. Turn-on loss in $\mathrm{Q} 1-\mathrm{Q} 4$

2. Turn-off loss in Q1-Q4

3. Recovery loss in D1-D4, and,

4. Conduction loss in Q1-Q4 and D1-D4

The turn-on power loss of Q1-Q4 depends on current $I_{\mathrm{a}}$ reflected at primary of TR whereas their turn-off loss depends on the value of current at turn-off moment i.e., the peak magnetizing current $I_{\mathrm{m}}$. The recovery loss of D1-D4 also depends on $I_{\mathrm{m}}$, plus presence of $l_{\mathrm{TR}}$ adds more losses to them. It is important to study the impact of STC on functioning of magnetically coupled inverter.

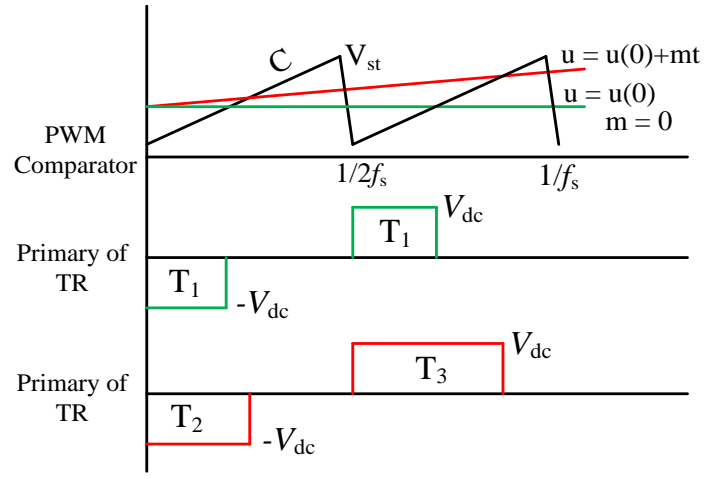

Fig. 7: Relation between slope of control function and PWM duty cycle

\section{A. Impact of Control Function on Transformer}

For design of TR, N87 Grade EE8020 cores were used. The primary to secondary turns ratio $\left(n_{\mathrm{p}}: n_{\mathrm{s}}: n_{\mathrm{s}}\right)$ was $15: 2: 2$. At $V_{\mathrm{DC}}$ of $580 \mathrm{~V}$, the value of peak operating flux density $B_{\mathrm{m}}$ for maximum value of $d_{\mathrm{pwm}}(=0.8)$ was $0.197 \mathrm{~T}$. At $100{ }^{\circ} \mathrm{C}$, the value of saturation flux density $B_{\text {sat }}$ was $0.39 \mathrm{~T}$. Among soft ferrites, linearity of B-H ( $H$ : magnetomotive force) curve of N87 Grade was found to be superior. To reduce the prospect of static volt-second unbalance in core [28], each IGBT pair (Q1, Q4) or (Q2, Q3) was driven by single pulse transformer. For variable $d_{\mathrm{pwm}}$, employing DC blocking capacitor in inverter would not be effective. Though the inverter was protected by cycle-by-cycle current limit, it was effective only at large current. The expression of peak magnetizing current $I_{\mathrm{m}}$ is,

$I_{m}=\frac{l_{\mathrm{mag}} B_{m}}{\mu_{0} \mu_{r} n_{p}}$

$B_{\mathrm{m}}$ is peak flux density, $n_{\mathrm{p}}$ is number of primary turns of TR, $l_{\text {mag }}$ is mean length of core and $\mu_{\mathrm{r}}$ is its relative permeability. $B_{\mathrm{m}}$ is directly linked to the control input, like,

$B_{m}=\frac{k_{1}}{4 A_{C} f_{s} n_{s}}\left(u_{\mathrm{STC}}\right.$ or $\left.u_{\mathrm{PI}}\right)$

$A_{\mathrm{C}}$ is core area and $n_{\mathrm{s}}$ is number of secondary turns.

Ideally, constant value of $u_{\mathrm{STC}}$ (slope $m=0$ ) in a cycle is desirable. Turn-on duration of $(\mathrm{Q} 1, \mathrm{Q} 4)$ or $(\mathrm{Q} 2, \mathrm{Q} 3)$ is same at, say, T1 (see Fig. 7) to ensure zero average flux in core. If $m$ is other than zero, turn-on duration (T2) in negative half cycle would be different from positive (T3) one (see Fig. 7, bottom). The flux variation $\Delta \Phi$ over one complete cycle is [26],

$\Delta \Phi=\frac{V_{\mathrm{DC}}\left(T_{2}-T_{3}\right)}{n_{p}}=\frac{V_{D C}}{n_{p}} \frac{m}{(C-m)} \frac{1}{2 f_{s}}$

The rate of change of flux density $\Delta B_{\mathrm{v}}$ caused by non-zero $m$ is,
$\Delta B_{\mathrm{v}}=\frac{V_{D C}}{2 A_{c} n_{p}} \frac{m}{(C-m)}$

$C$ is slope of sawtooth waveform with peak at $V_{\text {st }}$ (see Fig. 7) and $m$ is slope of $u_{\text {PI }}$ or $u_{\mathrm{STC}}$. The time $t_{\text {sat }}$ taken for core to attain the core saturation from operating peak $B_{\mathrm{m}}$ is

$t_{\text {sat }}=\frac{\left(B_{S a t}-B_{m}\right)}{\Delta B_{\mathrm{v}}}$

In this application, $B_{\mathrm{sat}} \approx 2 B_{\mathrm{m}}$. For reliable operation of the system the condition $t_{\mathrm{sat}}>\tau_{\mathrm{s}}$ (8) needs to be satisfied. If, by design, $m$ is kept comparable to $C$, swing in $B_{\mathrm{m}}$ in a cycle would be large where non-linearity in $B-H$ loop could play adverse impact. Actually, $m$ is considered small so that the value $\Delta B_{\mathrm{v}}$ in one complete cycle is negligible.

By design, the operating point of B-H curve is kept in linear zone and $I_{\mathrm{m}}$ depends on $d_{\mathrm{pwm}}$ i.e., control input. Drift in $I_{\mathrm{m}}$ in in each half-cycle would depend on the operating point of nonlinear B-H loop. For persistent non-zero value of $m$ the value of $d_{\text {pwm }}$ keeps increasing (see Fig. 8a) to make the operating $B-H$ loop shift towards one particular quadrant (see Fig. 8b) where the $B$ - $H$ curve for a particular half-cycle would be increasingly non-linear, leading to DC bias in core. The value of $\mu_{\mathrm{r}}$ (20) would be less in that half cycle, could lead to different value of $I_{\mathrm{m}}$ in positive and negative half-cycles. Fig. 8b shows that with positive $m$, DC bias in core is introduced where $H$ needed to maintain the flux swing is large i.e., the value of $I_{\mathrm{m}}$ is large. $I_{\mathrm{m}}$ does not contribute to power transfer but causes turn-off loss in Q1-Q4 and recovery losses in D1-D4, its minimum value is desired for reliable performance.

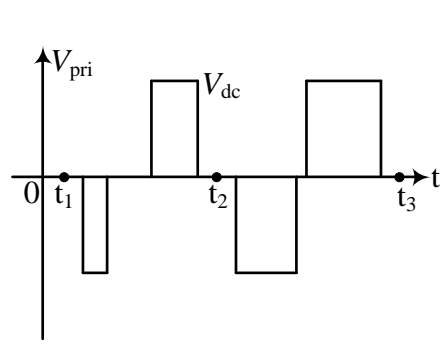

a)

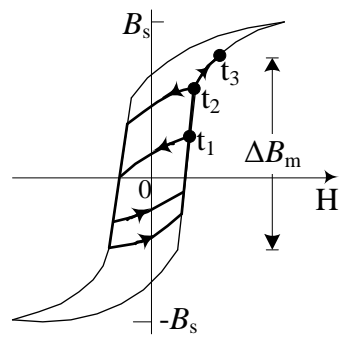

b)
Fig. 8: a) Primary voltage of TR with increasing PWM duty cycle, and, b) it shifts the operating hysteresis loop and creates of DC bias in core

\section{B. Influence of PI Control on Primary Current}

In FBC the current at secondary DC side is controlled. But, the actuation for control execution takes place at primary of TR. Ideally, the controller should be designed so that the $u_{\mathrm{PI}}$ does not disturb TR in its functioning for voltage translation in isolated manner. It is possible if the average flux in a PWM cycle is negligible. It is decided by the slope $m_{\mathrm{PI}}$ of $u_{\mathrm{PI}}$, like,

$m_{\mathrm{PI}}=k_{p} \frac{d e}{d t}+k_{i} e \approx k_{p} \frac{d e}{d t}=f\left(\frac{d e}{d t}\right)$

Where $d e / d t=k_{h s} d I_{a} / d t, k_{\mathrm{hs}}$ is constant for current to voltage conversion in hall sensor (10mV/A). Consider transient disturbance at $100 \mathrm{kA} / \mathrm{s}$ i.e., $d e / d t$ of $1000 \mathrm{~V} / \mathrm{s}$, here, with large value of $k_{\mathrm{p}}$ at 1.0 and $k_{\mathrm{i}}$ at 1000 , the value of $m_{\mathrm{PI}}$ is 1000 . Fig. $9 \mathrm{a}$ and $9 \mathrm{~b}$ show waveforms of primary current $I_{\text {pri }}$ of TR for two different applications. Unform waveform of $I_{\text {pri }}$ suggested that 
the controller-design based on secondary variables did not disturb the magnetic circuit of TR. The average flux inside the core was zero because the value of $I_{\mathrm{m}}$ was negligible. The peak value of $I_{\text {pri }}$ measured during turn-off at welding current $100 \mathrm{~A}$ was $14 \mathrm{~A}$, and for $200 \mathrm{~A}$, it was $27 \mathrm{~A}$. Current $I_{\text {pri }}$ and $I_{\mathrm{a}}$ were relatable as shown below:

$I_{\mathrm{Q} 1, \mathrm{Q} 4}=I_{\mathrm{Q} 2, \mathrm{Q} 3}=\frac{n_{s}}{n_{p}} I_{a}$

With $V_{\mathrm{st}}$ of $10 \mathrm{~V}$, for $20 \mathrm{kHz}$ inverter the maximum value of $C$ is 400000 where the value of $\Delta B_{\mathrm{v}}$ would be at $0.25 \%$ of $B_{\mathrm{m}}$.

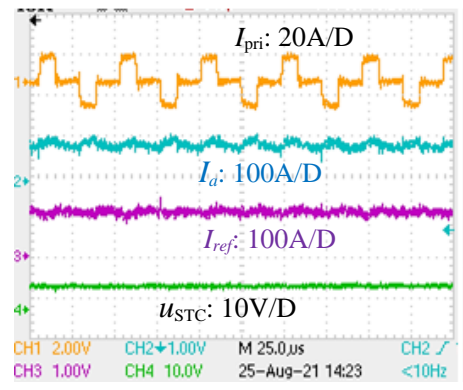

(a)

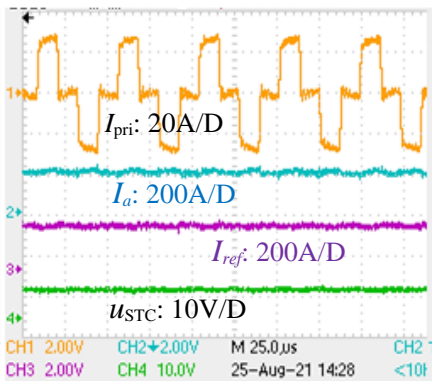

(b)
Fig. 9: Magnetic saturation or DC bias in core was absent under PI control, because there was no ripple in $u_{\mathrm{PI}}$ while welding at: a) $100 \mathrm{~A}$, and, b) $200 \mathrm{~A}$. [L1: $50 \mu \mathrm{H}$ and $C_{\mathrm{DC}}: 55 \mu \mathrm{F}, k_{\mathrm{p}}: 1.0$ and $\left.k_{\mathrm{i}}: 1000\right]$.

\section{Influence of STC on $I_{\text {pri }}$ when $C_{\mathrm{DC}}=55 \mu \mathrm{F}$ and $\mathrm{L} 1=50 \mu \mathrm{H}$}

The slope $m_{\mathrm{STC}}$ of $u_{\mathrm{STC}}$ is complex and quite different from $m_{\mathrm{PI}}$, it is difficult to define its trajectory. It is expressed as,

$m_{\mathrm{STC}}=\left(\frac{\rho_{01}}{2 \sqrt{e}} \frac{d e}{d t}+\rho_{11}\right) \operatorname{sgn}(e)=f\left(e, \frac{d e}{d t}, \operatorname{sgn}(e)\right)$

For same value of $d e / d t$ of $1000 \mathrm{~V} / \mathrm{s}$, the maximum value of $m_{\mathrm{STC}}$ is 28125 . The corrective measure is 28-time faster than PI. It is sensitive near zero error; even ripple in $I_{\mathrm{a}}$ could modulate $u_{\mathrm{STC}}$ at fast rate at frequency $2 f_{\mathrm{s}}$. The prospect of core saturation is high because the value of $\Delta B_{\mathrm{v}}$ is large, at $7.6 \%$ of $B_{\mathrm{m}}$.

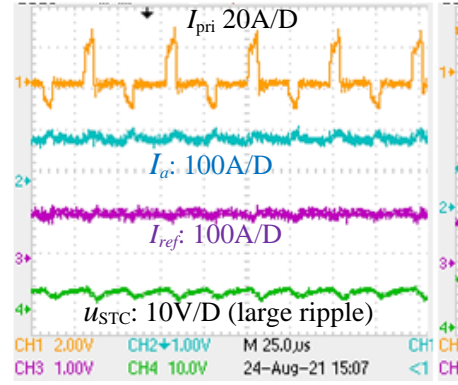

(a)

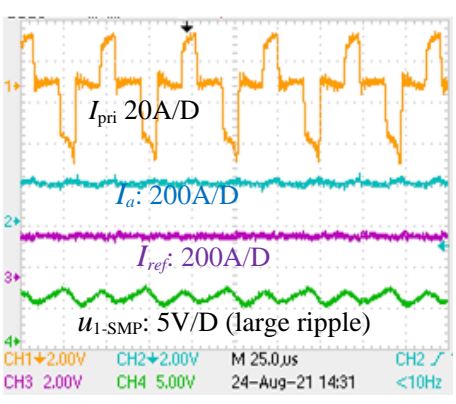

(b)
Fig. 10: High ripple content in high-gain $u_{\text {STC }}$ coupled with nonlinearity in B$\mathrm{H}$ curve of core resulted in DC bias and $I_{\mathrm{pri}}$ was more in one half-cycle, at, a) $100 \mathrm{~A}$, and, b) $200 \mathrm{~A}$.

Fig. 10 shows two sets of waveforms with same value of $C_{\mathrm{DC}}$ and L1 as used for PI control in Fig. 9. Even in steady state condition, due to large ripple in $V_{\mathrm{DC}}$ and, particularly, in $I_{\mathrm{a}}$ resulted large ripple in $u_{\text {STC }}$ (see Figs. 10a and 10b). High ripple in $u_{\mathrm{STC}}$ resulted DC bias in core and eqn. (26) was violated.

D. Influence of STC on $I_{\text {pri }}$ when LI or CDC was increased
In order to reduce the ripple in $I_{\mathrm{a}}$ as well as in $u_{\mathrm{STC}}$, the value of L1 and CDC were increased, one at a time. It is clear from Fig. 11 that, in steady state condition, the ripple content in $I_{\mathrm{a}}$ and $u_{\text {STC }}$ were only marginally reduced. Still, as shown in two welding conditions, $I_{\text {pri }}$ in each half cycle in both cases were quite different (see Figs. 11a and b). The current in one pair of IGBTs was different from the other and (26) was not met.

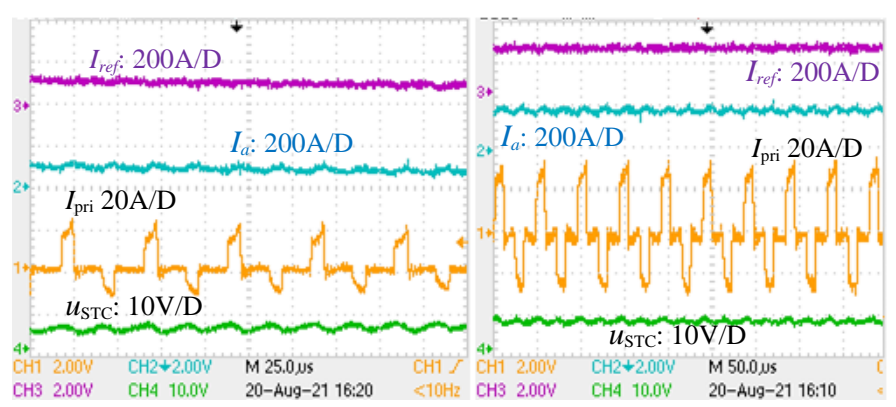

(a)

(b)

Fig. 11: a) While welding at $100 \mathrm{~A}$, ripple in $u_{\mathrm{STC}}$ was marginally reduced when $\mathrm{C}_{\mathrm{DC}}$ was increased to $110 \mu \mathrm{F}$, but DC bias in core persisted leading to unequal current in IGBT pairs and, b) when L1 was increased to $75 \mu \mathrm{H}$, similar results were achieved while welding at at $200 \mathrm{~A}$

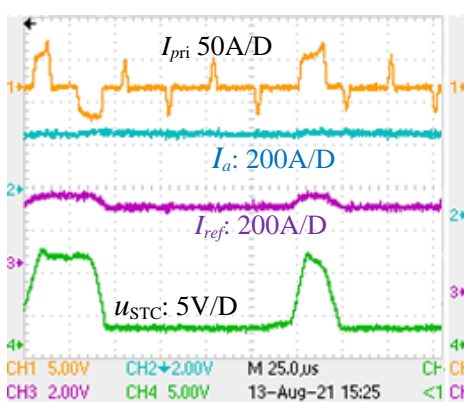

(a)

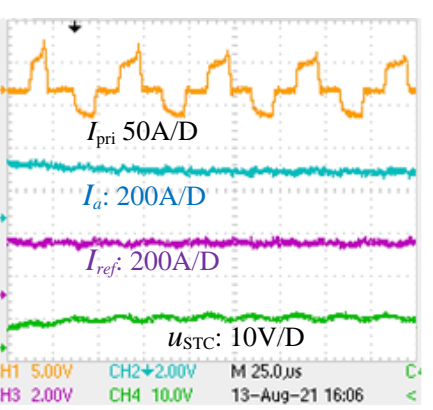

(b)
Fig. 12: a) When a transient boost in $I_{\text {ref }}$ was added to effect anti-sticking, STC resulted sharp change in $d_{\text {pwm }}$ within a single PWM cycle, leading to DC bias in core and unequal current in IGBT pairs, and, b) Same situation persisted even when $u_{\text {STC }}$ was getting stable after the transient condition, average flux in core per cycle was not zero. [L1: $75 \mu \mathrm{H} ; C_{\mathrm{DC}}: 110 \mu \mathrm{F}$ ].

\section{E. Influence of STC on $I_{\text {pri }}$ during Disturbance}

Here, to reduce ripple in $V_{\mathrm{DC}}, C_{\mathrm{DC}}$ was increased to $110 \mu \mathrm{F}$. Two experimental waveforms in Fig. 12 demonstrate the response of STC in presence of sharp transient disturbance for welding at 220A. Here, to create anti-sticking force during short-circuiting of electrode with weld pool $\left(V_{\mathrm{L}} \approx 0\right)$, transient reference equivalent to $d e / d t$ at $3000 \mathrm{~V} / \mathrm{s}$ was added. STC reacted sharply and changed the value of $d_{\text {pwm }}$ almost cycle-bycycle basis (see Fig. 12a). Large peak value of $I_{\text {pri }}$ in one pair of IGBT at $60 \mathrm{~A}(220 \%$ of PI) signified that current limit was operational. It resulted increase in conduction and highfrequency losses in inverter. Fig. 12b shows the behavior of $I_{\text {pri }}$ when $u_{\text {STC }}$ was gradually stabilizing from transient disturbance. The DC bias in core persisted because the operating point was already in nonlinear zone of $B-H$ loop.

\section{MOdified CONTROL Function to Boost EFFiCACY}

It was clear that $20 \mathrm{kHz}$ PI controller was reliable but it had overshoot and undershoot. To improve the control response the 
value of $f_{\mathrm{s}}$ is increased (8). Calculated values of different control parameters (see Table III) get better. Soft-switching topologies [29], [30] are employed to eliminate associated highfrequency losses. Power density of inverter also improves because the size of TR, L1 and heat sink are reduced.

TABLE III

CAPABILITY OF HIGH FREQUENCY PI BASED FBC

\begin{tabular}{|c|c|c|c|c|}
\hline Freq., $k \mathrm{~Hz}$ & 20 & 50 & 100 & 150 \\
\hline $\mathrm{L} 1, \mu \mathrm{H}$ & 65 & 25 & 14 & 9 \\
\hline$\tau_{\mathrm{s}}, \mu \mathrm{s}$ & 500 & 200 & 100 & 70 \\
\hline$k_{\mathrm{p}}$ & 0.13 & 0.112 & 0.128 & 0.125 \\
\hline$k_{\mathrm{i}}$ & 940 & 1950 & 4375 & 6330 \\
\hline$m_{\mathrm{PI}}$ & 130 & 224 & 640 & 1250 \\
\hline
\end{tabular}

STC could resolve the control related issues. But, even small disturbance or, ripple in $I_{\mathrm{a}}$ changed $u_{\mathrm{STC}}$ instantly resulting increase in power loss in magnetically coupled controller. There were concerns on reliability and availability features. Ideally, to cater wide range need of the process the theoretical value of two gains would be extremely large (see parameters in red ink in Table I). To avoid DC bias in core, respective value of $m_{\mathrm{STC}}$ (27) would need unrealistically large value of $C$ and $f_{\mathrm{s}}$ where PI performance would be great (see Table III).

It was noticed that the primary reasons for creation of DC bias in core and associated excess power loss in inverter were:

1. Extremely high gain near zero error (see Table II), and,

2. Existence of ripple in output, or ripple in error.

To make high-gain function reliable, $\mathrm{L} 1$ is increased to ensure ripple in $e$ (11) is under acceptable limit, and for soft corrective measure around zero error, following alternate control $u_{\mathrm{SMP}}$ [7], [15] of $u_{\mathrm{STC}}$ (14) is proposed,

$u_{S \mathrm{MP}}=\rho_{01} e+\rho_{11} \int \operatorname{sgn}(e) d \tau$

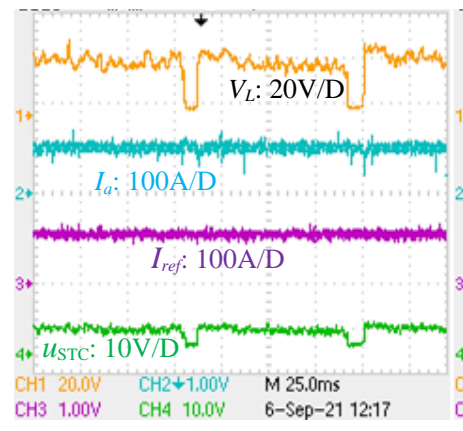

(a)

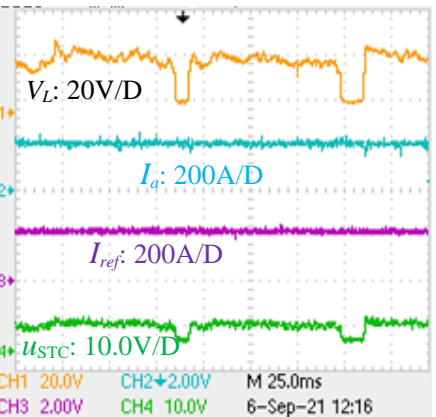

(b)
Fig. 13: Current control was robust when alternate function $u_{\mathrm{SMP}}$ with $\rho_{10}=5.0$ and $\rho_{11}=3125$ for welding at, a) $100 \mathrm{~A}$, and, b) 200A. [L1: $\left.100 \mu \mathrm{H}\right]$

It has been practically validated in several process applications [7], [19], [31] that (28) strongly meets conditions of (11). Here, like $m_{\mathrm{PI}}$, slope $m_{\mathrm{SMP}}$ of $u_{\mathrm{SMP}}$ depends on $d e / d t$ as,

$m_{\mathrm{SMP}}=\left(\rho_{01} \frac{d e}{d t}+\rho_{11}\right) \operatorname{sgn}(e)=f\left(\frac{d e}{d t}, \operatorname{sgn}(e)\right)$

For same value of $d e / d t$ of $1000 \mathrm{~V} / \mathrm{s}$, the maximum value of $m_{\mathrm{SMP}}$ is around 8000 . For $C$ at 400000 , compared to STC, the value of $\Delta B_{\mathrm{v}}$ was small at $2.0 \%$ of $B_{\mathrm{m}}$.

Fig. 13 shows control of current using new function (28) in similar applications (see Fig. 3, 5, 6), control responses were robust. Fig. 14 shows respective primary current $I_{\text {pri }}$. Though, same gains $\left(\rho_{10}: 5.0, \rho_{11}: 3125\right)$ of $u_{\mathrm{STC}}$ were used, but DC bias in core was negligible and conditions of (26) were satisfied.

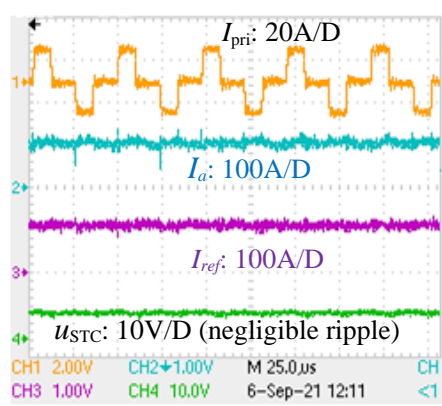

(a)

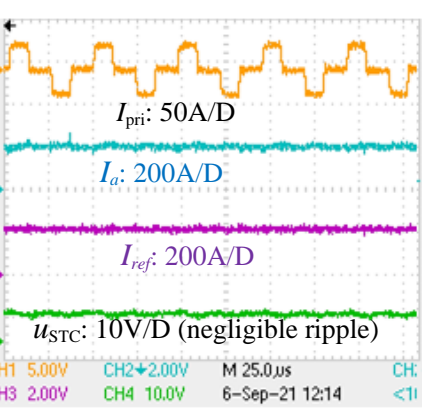

(b)
Fig. 14: DC bias in core was absent because the ripple in $u_{\mathrm{SMP}}$ was negligible, at: a) $100 \mathrm{~A}$, and, b) 200A. [L1: $100 \mu \mathrm{H}]$.

\section{CONCLUSION}

This article, for the first time, addressed the critical issues pertaining to the extremely slow pace of adoption and diffusion of widely researched STC concept. It detailed that efficacy of a new concept lied on their effective and efficient utilization to yield definite benefits. It further addressed that, apart from concept validation, commercialization of a product based on a novel idea needed to meet availability and reliability criteria. When the role of control was to directly modulate the duty cycle of PWM based converter, the control function that caused minimum stress to high-frequency power switching devices of a product would be preferred. It elaborated that the processdisturbance based gain selection procedure in STC might not be suitable for vast majority of products that used magnetically coupled power transfer mechanism. The high-gain STC could vary the duty cycle of PWM switches in each half-cycle, it was also highly sensitive to output ripple. Such fast change in duty cycle could inject DC bias in magnetic circuit of transformer that caused excess power loss in inverter. On the other hand, the choice of gains in PI control was more collective. It, not only involved the process dynamics, parameters of power controller were part of the design; smoothing inductance and switching frequency of inverter were part of gain selection.

\section{REFERENCES}

[1] T. G. Wilson, "The evolution of power electronics," IEEE Trans. Power Electron., vol. 15, no. 3, pp. 439-446, May 2000, doi: 10.1109/63.844503.

[2] J. A. Ferreira and J. D. Van Wyk, "Electromagnetic energy propagation in power electronic converters: toward future electromagnetic integration," Proc. IEEE, vol. 89, no. 6, pp. 876-889, June 2001, doi: $10.1109 / 5.931481$.

[3] M. Vilathgamuwa, D. Nayanasiri and S. Gamini, Power Electronics for Photovoltaic Power Systems, Morgan \& Claypool, 2015.

[4] K. Yamamoto, E. Hiraki, T. Tanaka, M. Nakaoka and T. Mishima, "Bidirectional DC-DC converter with full-bridge/push-pull circuit for automobile electric power systems," in Conf. Proc. IEEE PESC, 2006, pp. 1-5, doi: 10.1109/pesc.2006.1711776.

[5] L. Corradini and D. Maksimović, "A digital pulse-width modulator for phase-shift operation of full-bridge isolated DC-DC converters," Conf. Prof. IEEE APEC, 2010, pp. 277-283, doi: 10.1109/APEC.2010.5433660.

[6] S.-J. Jeon and G.-H. Cho, "A zero-voltage zero-current switching full bridge DC-DC converter with transformer isolation”, IEEE Trans. Power Electron., vol. 16, issue 5, 2001, pp. $573-580$. 
[7] A. K. Paul, "Robust product design using SOSM for control of shielded metal arc welding (SMAW) process," IEEE Trans. Ind. Electron., vol. 63, no. 6, pp. 3717-3724, Jun. 2016.

[8] M. Pahlevani and P. K. Jain, "Soft-switching power electronics technology for electric vehicles: A technology review," IEEE J. Emerg. Sel. Top. Ind. Electron., vol. 1, no. 1, pp. 80-90, July 2020, doi: 10.1109/JESTIE.2020.2999590.

[9] B. Sai Ram, A.K. Paul, S.V. Kulkarni, "Soft Magnetic Materials and their Applications in Transformers," J Magn. Magn. Mater., vol. 537, pre-print, pp. 1-13, 2021, https://doi.org/10.1016/j.jmmm.2021.168210.

[10] S. Ziegler, R. C. Woodward, H. H. Iu and L. J. Borle, "Current Sensing Techniques: A Review," in IEEE Sensors Journal, vol. 9, no. 4, pp. 354376, April 2009, doi: 10.1109/JSEN.2009.2013914.

[11] H. -J. Guo, Y. Shiroishi and O. Ichinokura, "Digital PI controller for high frequency switching DC/DC converters based on FPGA," Conf. Proc. INTELEC '03., pp. 536-541, 2003, IEEE.

[12] K. J. Astrom, Control system Design, Ch. 4, Lecture notes, 2002.

[13] J.-K. Seok, K.-T. Kim and D.-C. Lee, "Automatic mode switching of P/PI speed control for industry servo drives using online spectrum analysis of torque command," IEEE Trans. Ind. Electron., vol. 54, no. 4, pp. 26422647, April, 2007.

[14] "Setting the P-I Controller Parameters, KP and KI", Application note TLE7242 and TLE8242, Infineon Technologies, Oct. 2009.

[15] S. C. Mahto et al., "Nonsmooth PI controller for uncertain systems," IEEE Access, vol. 8, pp. 124792-124801, 2020, doi: 10.1109/ACCESS.2020.3007767.

[16] A. Levant, "Sliding order and sliding accuracy in sliding mode control", Int. J. Control, vol. 58, no. 6, pp. 1247-1263, 1993.

[17] A. K. Paul and B. Bandyopadhyay, "Multi-Functional Arc Welding Controller using SOSMC Technique," IEEE Trans. Control Syst. Technol., vol. 27, no. 5, pp. 2245-2253, 2018.

[18] T. Gonzalez, J. A. Moreno and L. Fridman. "Variable gain super-twisting sliding mode control," IEEE Trans. Automatic Control, vol. 57, no. 8, pp. 2100-2105, Aug. 2011.

[19] A. K. Paul, "Sensorless robust speed controller design of pancake axial field PMDC motor," IEEE Trans. Ind. Appln., vol. 55, no. 6, pp. 5981$5989,2019$.

[20] D. B. Morales, R. Delpoux, V. Léchappé and J. D. L. Morales, "SingleGain Super-Twisting Algorithm Application to PMSM," IEEE J. Emerg. Sel. Top. Ind. Electron., vol. 2, no. 3, pp. 237-246, July 2021, doi: 10.1109/JESTIE.2021.3051589.

[21] J. A. Moreno and M. Osorio, "A Lyapunov approach to second-order sliding mode controllers and observers," in 2008 47th IEEE conference on decision and control, pp. 2856-2861. IEEE, 2008.

[22] R. Seeber and M. Horn, "Stability proof for a well-established supertwisting parameter setting," Automatica, vol. 84, pp. 241-243, Oct. 2017.

[23] S.-C. Tan and Y. M. Lai, "General design issues of sliding-mode controllers in DC-DC converters", IEEE Trans. Ind. Electron., vol. 55, issue 3, 2008, pp. $1160-1174$.

[24] Zhiqiang Gao and R. R. Rhinehart, "Theory vs. practice: The challenges from industry," Conf. Proc. IEEE ACC, 2004, pp. 1341-1349, doi: 10.23919/ACC.2004.1386761.

[25] A. K. Paul, "Capability, flexibility, and legacy of PI hinder market penetration prospect of SOSM for control of GMAW process," IEEE Trans. Ind. Appln., vol. 52, no. 1, pp. 384 - 394, Jan./Feb. 2016.

[26] T. Kohama, S. Tokimatsu and H. Shimamori, "Elimination of magnetic saturation due to fast dynamic response in DC-DC converter," Proc. INTELEC, 2009, pp. 1-6, doi: 10.1109/INTLEC.2009.5351916.

[27] G. Ortiz, L. Fässler, J. W. Kolar and O. Apeldoorn, "Flux balancing of isolation transformers and application of "the magnetic ear" for closedloop volt-second compensation," IEEE Trans. Power Electron., vol. 29, no. 8, pp. 4078-4090, Aug. 2014, doi: 10.1109/TPEL.2013.2294551.

[28] D. Costinett, D. Seltzer, D. Maksimovic and R. Zane, "Inherent voltsecond balancing of magnetic devices in zero-voltage switched power converters," Conf. Proc. 18 ${ }^{\text {th }}$ IEEE APEC, 2013, pp. 9-15, doi: 10.1109/APEC.2013.6520178.

[29] J. Dudrik, M. Bodor and M. Pastor, "Soft-switching full-bridge PWM DC-DC converter with controlled output rectifier and secondary energy recovery turn-off snubber", IEEE Trans. Power Electron., vol. 29, no. 8, pp. 4116-4125, Aug 2014.

[30] A. Navarro-Crespin, V. M. Lopez, R. Casanueva and F. J. Akcondo, "Digital control for an arc welding machine based on resonant converters and synchronous rectification," IEEE Trans. Ind. Informatics., vol. 9, pp. 839-847, 2013.
[31] A. K. Paul, M. K. Bera, M. Waman and B. Bandyopdhyay, "Industrygrade robust controller design for constant voltage arc welding process," A. Mehta and B. Bandyopadhyay (eds), Emerging Trends in Sliding Mode Control. Studies and Systems, Decision and Control, vol. 218, pp. 393417, Springer, Singapore, 2021. doi.org/10.1007/978-981-15-8613-2_16. 